\title{
ANALISIS KESULITAN SISWA BERDASARKAN KEMAMPUAN PEMAHAMAN MATEMATIK DALAM MENGERJAKAN SOAL PADA MATERI BANGUN RUANG SISI DATAR
}

\author{
Nurfitri Badraeni ${ }^{1}$, Regi Ayu Pamungkas ${ }^{2}$, Wahyu Hidayat ${ }^{3}$, Euis Eti Rohaeti ${ }^{4}$ Tommy Tanu Wijaya $^{5}$ \\ 1,2,3,4 IKIP Siliwangi, Jl Jenderal Sudirman, Cimahi, Jawa Barat, Indonesia \\ ${ }^{5}$ Guangxi Normal University, Guilin, China \\ badraeniocha1998@gmail.com
}

\begin{abstract}
The aim of this research is to find out Mts Nurul Hidayah 8th grade students' understanding ability on the topic of polyhedron. For base of next research for improving students' understanding ability on the topic of polyhedron. The samples for this research are 28 8A class students from Mts Nurul Hidayah from the year 2018/2019. The method that will be use in this research is a descriptive qualitative research. Based on the test result of the 4th question, students have the tendency to not connect a concept or principal to another. The result obtained falls into the 'lacking' category with a result of $37.85 \%$. The test result shows that in the 5th question, the students have a hard time in applying the formula into simple and algorithmic calculation. The result obtained also falls into the 'lacking' category with a result of $28.57 \%$. With this we can conclude that the difficulties faced by the students while doing the 4th and 5th question is they were not able to connect a concept or principal to another and did not apply the formula when doing a simple and algorithmic calculation.
\end{abstract}

Keywords: mathematical understanding ability

\begin{abstract}
Abstrak
Tujuan dari penelitian ini adalah untuk menganalisis kesulitan siswa berdasarkan indikator kemampuan pemahaman konsep matematis siswa pada materi bangun ruang sisi datar. Penelitian ini akan dijadikan sebagai studi pendahuluan dalam penelitian meningkatkan kemampuan pemahaman konsep matematis siswa pada materi bangun ruang sisi datar. Populasi penelitian adalah siswa kelas VIII di Mts Nurul Hidayah tahun ajaran 2018/2019. Metode penelitian ini adalah penelitian deskriptif kualitatif. Pengumpulan data diambil dari hasil tes soal kemampuan pemahaman yang telah diberikan. Berdasarkan hasil tes soal ke 4 siswa cenderung tidak mengaitkan satu konsep atau prinsip dengan konsep atau prinsip lainnya dengan hasil presentase yang diperoleh $37,85 \%$ termasuk ke dalam kategori sangat kurang. Dan hasil tes soal ke 5 siswa cenderung tidak dapat menerapkan rumus dalam perhitungan sederhana dan mengerjakan perhitungan secara algoritmik (pemahaman instrumental) dengan hasil presentase yang diperoleh 28,57\% termasuk ke dalam kategori sangat kurang. Dapat disimpulkan bahwa kesulitan siswa berdasarkan kemampuan matematis dalam menyelesaikan soal bangun ruang sisi datar pada saat mengerjakan soal ke 4 dan soal ke 5 karena siswa tidak mengaitkan satu konsep atau prinsip dengan konsep atau prinsip lainnya dan tidak menerapkan rumus dalam perhitungan sederhana dan mengerjakan perhitungan secara algoritmik .
\end{abstract}

Kata kunci: Kesulitan Siswa, Kemampuan Pemahaman Matematik

\section{PENDAHULUAN}

Pemahaman matematis diterjemahkan dari istilah mathematical understanding merupakan kemampuan matematis yang amat sangat penting dan harus dimiliki setiap siswa dalam melaksanakan pembelajaran matematika. Karena sering Belajar matematika dapat melatih kemampuan siswa dalam menghubungkan suatu konsep matematika ke konsep lain (Dini, Wijaya, and Sugandi 2018). Pentingnya kepemilikan pemahaman oleh siswa dikemukakan Santrock (2008), bahwa pemahaman konsep adalah aspek kunci dari pembelajaran. Selain itu, pemahaman matematis penting untuk belajar matematika secara bermakna. Indikator pemahaman matematis siswa dibagi menjadi 5 kategori yaitu: Menerapkan rumus dalam perhitungan sederhana dan mengerjakan perhitungan secara pemahaman 
instrumental, Mengaitkan satu konsep atau prinsip dengan konsep atau pemahaman relasional, Mengaitkan satu konsep atau prinsip dengan konsep atau pemahaman relasional, Mengaitkan satu konsep atau prinsip dengan konsep atau prinsip lainnya, Menerapkan rumus dalam perhitungan sederhana dan mengerjakan perhitungan secara pemahaman instrumental (Dewi et al. 2018).

Materi yang disampaikan terhadap siswa tidak berupa sekedar hafalan, namun akan lebih mengerti konsep materi dengan pemahaman siswa yang sedang dipelajari, berpikir untuk menyelesaikan persoalan matematika ataupun masalah di dunia nyata (Dewi et al. 2018). Tujuan dari apa yang disebutkan oleh guru kepada siswa, merupakan pemahaman matematis. karena guru adalah pembimbing bagi siswa agar dapat mencapai suatu konsep yang diharapkan.

Pendidikan yang baik ialah usaha yang membuat siswa berhasil serta membawa siswa kepada tujuan agar para siswa dapat menyelesaikan persoalan pada kehidupan sehari-hari (Dewi et al. 2018). Indonesia menempati peringkat 64 dari 65 negara yang berpartisipasi dan memperoleh skor 375 dari rata-rata skor yang ditetapkan Organisation for Economic Cooperation and Development (OECD) yaitu 494 untuk kemampuan literasi matematika (Andini et al. 2018). hasil penelitian internasional pada tahun 2015 Mathematic and Science Study (TIMSS) menunjukkan bahwa kemampuan matematika siswa Indonesia berada di peringkat 44th dari 49 negara dengan score 397 (Hutajulu, Wijaya, and Hidayat 2019). Kemampuan pemahaman matematis merupakan dasar penting dalam pembelajaran . Oleh karena itu, maksud dalam penelitian ini, ingin membantu siswa untuk menganalisis jenis kesulitan apa saja yang siswa alami dalam menyelesaikan masing-masing soal tes uraian bangun ruang dengan menganalisis penyebab kesulitan tersebut kita akan paham apa yang dirasakan oleh siswa agar meminimalisasi apa saja kesulitan yang siswa rasakan dalam mengerjakan soal uraian.

\section{METODE}

Metode yang digunakan pada penelitian ini adalah deskriptif kualitatif yang bertujuan untuk menganalisis kesulitan siswa dalam mengerjakan soal-soal uraian pemahaman matematis pada materi bangun ruang sisi datar. Penelitian yang menggunakan penelitian kualitatif bertujuan untuk memahami objek yang diteliti secara mendalam (Aminah, Wijaya, and Yuspriyati 2018;Zuyyina, Wijaya, and Senjawati 2018). Penelitian ini dilaksanakan di Mts Nurul Hidayah yang bertempat di Jalan Sukamaju Batujajar. dengan subjek penelitian adalah di kelas VIII A.

Prosedur tahapan penelitian ini meliputi: 3P yaitu perencanaan,pelaksanaan, dan pengamatan. Perencanaan yaitu kegiatan menyusun instrumen dan melakukan validasi. Kegiatan pada pelaksanaan, memberikan beberapa soal tes uraian kemampuan pemahaman mengenai materi yang telah disampaikan. Pengamatan yaitu kegiatan menganalisis kesulitan siswa dalam mengerjakan sol-soal kemampuan pemahaman matematis. Instrumen yang digunakan berupa beberapa soal tes pemahaman terdiri dari 5 butir soal berbentuk uraian. Tes soal uraian ini untuk mengukur atau mengetahui pemahaman siswa di kelas tersebut.

Siswa yang mampu mengerjakan dengan benar berarti memiliki nilai pemahaman yang baik. 
Menurut Putra (2016) soal yang akan diujikan pada siswa harus memenuhi indikator pemahaman yang ditetapkan. Soal pertama dengan indikator menerapkan rumus dalam perhitungan sederhana dan mengerjakan perhitungan pemahaman instrumental. Soal kedua dengan indikator mengaitkan satu konsep atau prinsip dengan konsep atau pemahaman relasional. Soal ketiga dengan indikator mengkaitkan satu konsep atau prinsip dengan konsep atau pemahaman relasional. Soal keempat dengan indikator mengkaitkan satu konsep atau prinsip dengan konsep atau prinsip lainnya. Soal kelima dengan indikator menerapkan rumus dalam perhitungan sederhana dan mengerjakan perhitungan pemahaman instrumental. Penilaian presentase menurut Purwanto (2009: 102) :Bagian metode ini memuat jenis penelitian, subjek penelitian, instrument pengumpulan data, dan analisis data. Disamping judul, template menyediakan style heading untuk setiap judul dalam manuscript: heading 1 , heading 2 , dan heading 3 (Gunakan Microsoft Word template style: Heading 1). Heading ini hanya merupakan guidelines dan bukan bagian dari judul manuscript.

$\mathrm{NP}=\frac{R}{S M} \mathrm{X} 100 \%$

Keterangan:

NP : Nilai presentase yang dicari

$\mathrm{R} \quad$ : Nilai yang didapat siswa

SM : Nilai tertinggi atau ideal

\section{Tabel 1.}

Pedoman penskoran kemampuan pemahaman siswa (Nopriyanti., 2003; Sofyadin, 2019).

\begin{tabular}{|c|c|}
\hline Kategori & Skor (\%) \\
\hline Sangat baik & $86-100$ \\
\hline Baik & $76-85$ \\
\hline Cukup & $60-75$ \\
\hline Kurang & $55-59$ \\
\hline Sangat kurang & $\leq 54$ \\
\hline
\end{tabular}

\section{HASIL}

Hasil analisis dari data deskriptif kualitatif didapat dengan melihat langkah penyelesaian soal yang telah dikerjakan siswa melalui tes agar terlihat dimana faktor kesalahan dan kesulitan tersebut. Menurut cooney (Abdurrahman, 2009 : 278) mengemukakan kesulitan pada umumnya terletak pada kurangnya pemahaman konsep dan prinsip dalam matematika. Untuk penyebab kesulitan yang dialami siswa saat mengerjakan siswa kurang menguasai materi, salah dalam menuliskan rumus permukaan balok.

Setelah diteliti ternyata bahwa siswa tersebut belum memahami cara menyelesaikan persoalan tersebut dengan benar. Belum paham tentang langkah-langkah soal dan indikator kemampuan pemahaman yaitu menerapkan rumus dalam perhitungan. 
Tabel 2.

Rekapitulasi Hasil Tes

\begin{tabular}{|c|l|c|}
\hline Soal & \multicolumn{1}{|c|}{ Indikator } & Presentase \\
\hline Soal ke 1 & $\begin{array}{l}\text { Menerapkan rumus dalam perhitungan sederhana dan } \\
\text { mengerjakan perhitungan secara pemahaman instrumental. }\end{array}$ & $88,57 \%$ \\
\hline Soal ke 2 & $\begin{array}{l}\text { Mengaitkan satu konsep atau prinsip dengan konsep atau } \\
\text { pemahaman relasional. }\end{array}$ & $60,71 \%$ \\
\hline Soal ke 3 & $\begin{array}{l}\text { Mengaitkan satu konsep atau prinsip dengan konsep atau } \\
\text { pemahaman relasional. }\end{array}$ & $66,96 \%$ \\
\hline Soal ke 4 & $\begin{array}{l}\text { Mengaitkan satu konsep atau prinsip dengan konsep atau prinsip } \\
\text { lainnya. }\end{array}$ & $37,85 \%$ \\
\hline Soal ke 5 & $\begin{array}{l}\text { Menerapkan rumus dalam perhitungan sederhana dan } \\
\text { mengerjakan perhitungan secara pemahaman instrumental. }\end{array}$ & $28,57 \%$ \\
\hline
\end{tabular}

Dapat dilihat dari analisis data pada tabel 2 dalam butir soal ke satu dengan indikator tersebut, hasil nilai presentase yang di dapat dari seluruh siswa mencapai $88,57 \%$ termasuk ke dalam kategori sangat baik. Pada butir soal kedua dengan indikator tersebut, hasil nilai presentase yang di diperoleh dari seluruh siswa mencapai 60,71\% termasuk kategori cukup. Pada butir soal ke tiga dengan indikator tersebut, hasil nilai presentase yang di dapat dari seluruh siswa mencapai $66,96 \%$ termasuk ke kategori cukup. Pada butir soal ke empat dengan indikator tersebut, hasil nilai presentase yang di dapat dari seluruh siswa mencapai 37,85\% termasuk ke kategori sangat kurang. Pada butir soal ke lima dengan indikator tersebut, hasil nilai presentase yang di dapat dari seluruh siswa mencapai $28,57 \%$ termasukm kategori sangat kurang. Hal ini menunjukan bahwa seluruh siswa kesulitan dalam menjawab soal ke 4 dan soal ke 5 karena termasuk kategori sangat kurang.

Salah satu hasil siswa yang kurang tepat pada butir soal ke 1 dengan indikator.

Diketahui sebuah balok $A B C D$.EFGH dengan panjang $A B=10 \mathrm{~cm}, B C=4$
$\mathrm{~cm}$, dan luas sisi $B C G F=28 \mathrm{~cm}^{2}$. Hitunglah luas pemukaan baiok
$A B C D, E F G H$ tersebut!

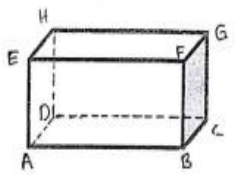

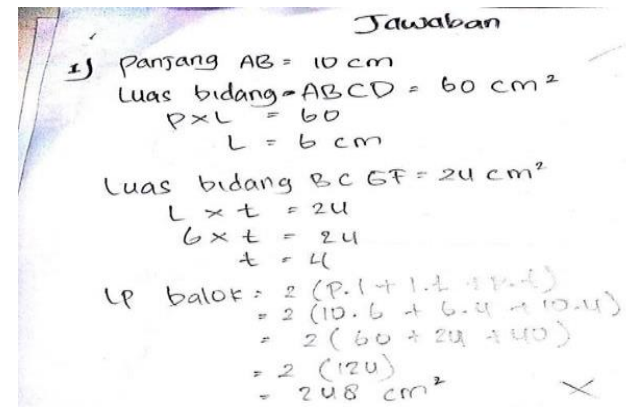

Gambar 1. Hasil siswa pada butir soal ke 1

Dilihat dari Gambar ke 1, kesulitan siswa dalam mengerjakan soal ke 1 siswa sudah bisa mengidentifikasi data yang diketahui tetapi belum mampu menerapkan rumus dan belum bisa mengerjakan perhitungan secara algoritmik (pemahaman instrumental). Siswa keliru dalam menentukan cara mencari tinggi dari balok. Dan keliru mengerjakan hasil akhir untuk mencari permukaan balok.

Salah satu hasil siswa yang kurang tepat pada butir soal ke 2 dengan indikator 
2. Kemasan kotak pasta gigi dengan netto $75 \mathrm{~g}$ yang berukuran panjang $20 \mathrm{~cm}$, lebar $4 \mathrm{~cm}$, dan tinggi $6 \mathrm{~cm}$ dimasukkan ke dalam sebuah dus dengan susunan seperti gambar di bawah ini. Hitunglah luas permukaan dus tersebut jika berisi 12 kemasan kotak pasta gigi !

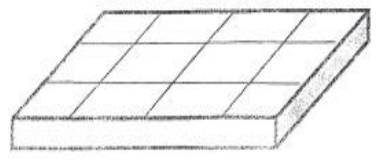

Gambar 2. Hasil siswa pada butir soal ke 2

Dari gambar ke 2, kesulitan siswa dalam mengerjakan soal ke 2 siswa tidak menuliskan data yang diketahui dan tidak mengaitkan satu konsep ke konsep lainnya (pemahaman relasional).

Salah satu hasil siswa yang kurang tepat pada butir soal ke 3 dengan indikator.
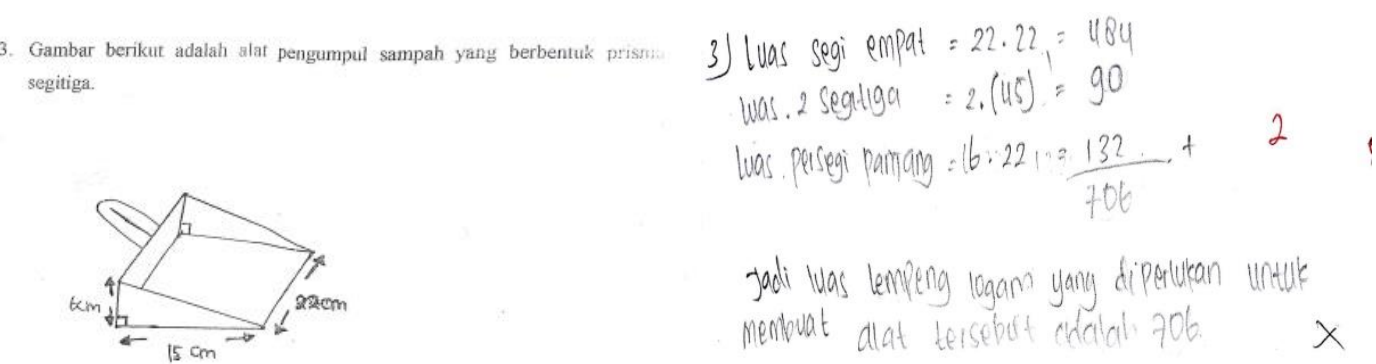

Gambar 3. Hasil siswa pada butir soal ke 3

Dari gambar ke 3, kesulitan siswa dalam mengerjakan soal ke 3, siswa tidak bisa mengidentifikasi data yang diketahui dan tidak mengaitkan satu konsep ke konsep lainnya (pemahaman relasional). Dari hasil jawaban diatas siswa bingung dalam menentukan konsep matematika untuk luas lempeng logam. Salah satu hasil siswa yang kurang tepat pada butir soal ke 4 dengan indikator.

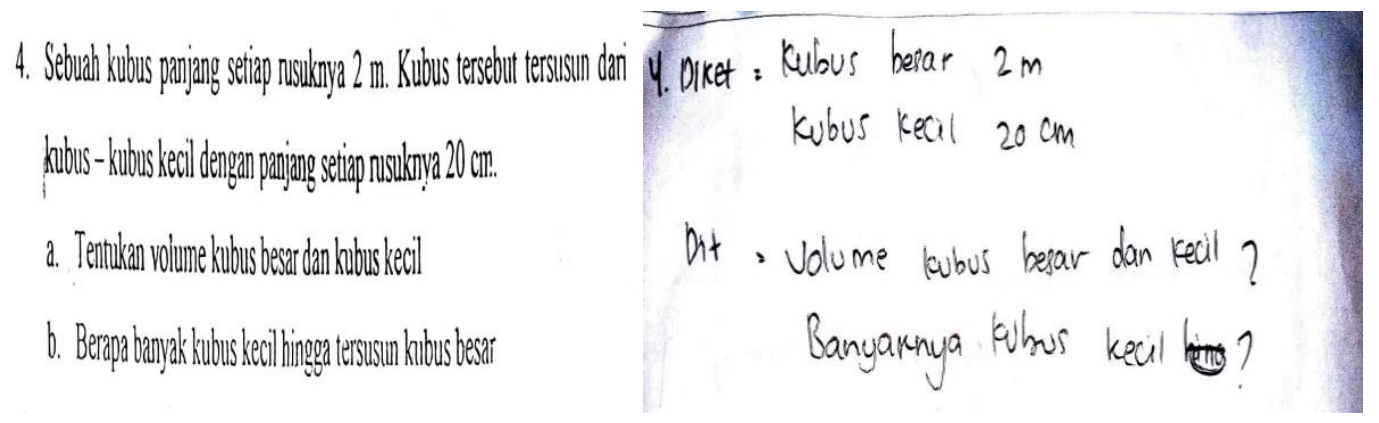

Gambar 4. Hasil siswa pada butir soal ke 4

Berdasarkan Gambar ke 4, kesulitan siswa dalam mengerjakan soal ke 4 siswa tidak mengaitkan satu konsep atau prinsip dengan konsep atau prinsip lainnya. Dilihat dari jawaban diatas siswa hanya menulis diketahui dan ditanyakan saja tanpa mencoba mengerjakan jawabannya. 
Salah satu hasil siswa yang kurang tepat pada butir soal ke 5 dengan indikator.
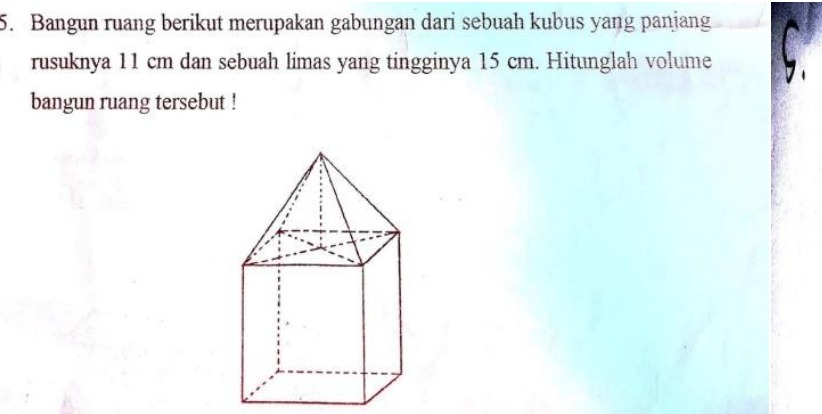

Gambar 5. Hasil siswa pada butir soal ke 5

Berdasarkan Gambar ke 5, hasil yang di dapat siswa saat mengerjakan soal ke 5, siswa tidak menerapkan rumus yang telah dijelaskan sebelumnya. Dilihat dari jawaban diatas siswa tidak mengetahui rumus volume bangun ruang tersebut sehingga siswa tidak mencoba mengerjakan soal tersebut. Berdasarkan uraian diatas hasil analisis dari kesulitan tersebut dilihat bahwa siswa banyak mengalami kesulitan pada saat menjawab soal ke 4 dan 5 dengan indikator yang sudah dijelaskan sebelumnya.

\section{KESIMPULAN}

Berdasarkan penelitian yang sudah dilaksanakan dapat disimpulkan bahwa faktor kesulitan siswa pada saat mengerjakan soal tes tentang bangun ruang sisi datar untuk mengetahui kemampuan pemahaman matematis masih sangat kurang karena siswa tidak begitu memahami soal dan konsep matematika. Berdasarkan pembahasan diatas, saran untuk guru yang mengajar harus mengetahui dimana saja letak kesulitan yang siswa alami dalam menyelesaikan soal yang diberikan dan untuk siswa harus memperbanyak latihan mengerjakan soal agar dapat melatih keterampilan. Penelitian ini semoga jadi gambaran untuk para peneliti selanjutnya tentang kesulitan yang siswa alami pada saat mengerjakan soal materi bangun ruang sisi datar.

\section{DAFTAR PUSTAKA}

Alan, F. Fauzan, Afriansyah, A. Ekastya. (2017). Kemampuan Pemahaman Matematis Siswa Melalui Model Pembelajaran Auditory Intellectually Repetition dan Problem Based Learning. Ejournal Unstri Garut: STKIP Garut

Aminah, Siti, Tommy Tanu Wijaya, and Devi Yuspriyati. (2018). "Analisis Kemampuan Komunikasi Matematis Siswa Kelas Viii Pada Materi Himpunan.” Jurnal Cendekia: Jurnal Pendidikan Matematika 2(1): 15-22. doi: https://doi.org/10.31004/cendekia.v2i1.29

Andini, Dwi, Nenden Mulyani, Tommy Wijaya, and Devi Supriyati. (2018). "Meningkatkan Kemampuan Komunikasi Matematis Dan Self Confidence Siswa Menggunakan Pendekatan PBL 
Berbantuan Geogebra.” Jurnal Derivat: Jurnal Matematika dan Pendidikan Matematika 5(1): 82 93.

Dewi, Senja Noviani, Tommy Tanu Wijaya, Ayu Budianti, and Euis Eti Rohaeti. (2018). "Pengaruh Model Teams Games Tournament Terhadap Kemampuan Pemahaman Matematik Siswa Kelas XI SMK Di Kota Cimahi Pada Materi Fungsi Eksponen.” WACANA AKADEMIKA: Majalah Ilmiah Kependidikan 2(1): 99.

Dini, M., Wijaya, T., \& Sugandi, A. (2018). PENGARUH SELF CONFIDENCE TERHADAP KEMAMPUAN PEMAHAMAN MATEMATIK SISWA SMP. JURNAL SILOGISME : Kajian Ilmu Matematika dan Pembelajarannya, 3(1), 1-7. doi:http://dx.doi.org/10.24269/js.v3i1.936 Hutajulu, Masta, Tommy Tanu Wijaya, and Wahyu Hidayat. 2019. "The Effect of Mathematical Disposition and Learning Motivation on Problem Solving: An Analysis." Infinity Journal 8(2): 229.

Nopriyanti. (2003). Upaya Meningkatkan Aktivitas Dan Hasil Belajar Siswa Dengan Menggunakan Model Pembelajaran Kooperatif Tipe Numbered Heads Together (Nht) Pada Kompetensi Mesin Konversi Energi Kelas X Smk N 2 Kayu Agung. JURNAL PENDIDIKAN TEKNIK MESIN, $3(2), 146-157$.

Putra, D. Hari, Dkk. (2018). Kemampuan Pemahaman Matematis Siswa SMP di Bandung Barat. Cimahi : Pendidikan Matematika IKIP Siliwangi

Ramdani, M., \& Apriansyah, D. (2018). Analisis Kemampuan Pemahaman dan Berfikir Kreatif Matematik Siswa Mts pada Materi Bangun Ruang Sisi Datar. Jurnal Cendekia: Jurnal Pendidikan Matematika, 2(2), 1-7.

Sofyadin, R. T. (2019). Implementation The Problem Based Learning Models To Improve Learning Outcomes Of XI Iis 1 Class 2 State High School Students Baubau Southeast Sulawesi. LA GEOGRAFIA, 17(3).

TT Wijaya, NSS Dewi, IR Fauziah, M. Afrilianto. (2018). Analisis Kemampuan Pemahaman Matematis Siswa Kelas IX Pada Materi Bangun Ruang. Pendidikan Matematika. Jurnal ilmiah pendidikan matematika . Doi:http://dx.doi.org/10.30738/.v6i1.2076

Zuyyina, H., Wijaya, T., P, H., \& Senjawati, E. (2018). KEMAMPUAN KONEKSI MATEMATIS SISWA SMP PADA MATERI LINGKARAN. SOSIOHUMANIORA: Jurnal Ilmiah Ilmu Sosial Dan Humaniora, 4(2). doi:http://dx.doi.org/10.30738/sosio.v4i2.2546 